\title{
Retrofitting Office Buildings: Enhancing daylighting performance with switchable ETFE double-skin façades
}

\author{
Jan-F. Flor*, Yanyi Sun ${ }^{\dagger}$, Paolo Beccarelli ${ }^{\dagger}$, Yupeng Wu ${ }^{\dagger}$ and John Chilton ${ }^{\dagger}$ \\ 19, Jalan SS1/29, Kampung Tunku, \\ 47300 Petaling Jaya, Selangor, Malaysia \\ e-mail: janflor@gmx.de,web page: https://orcid.org/0000-0001-8740-5227 \\ ${ }^{\dagger}$ Department of Architecture \& Built Environment (DABE) \\ The University of Nottingham (UoN) \\ University Park, Nottingham NG7 2RD, United Kingdom \\ Email: john.chilton@nottingham.ac.uk -Web page: https://www.nottingham.ac.uk/
}

\begin{abstract}
The research reported in this paper addresses the natural daylighting qualities of spaces enclosed by ETFE multi-layer foil constructions with switchable features. The study focuses on the effects the adaptive shading mechanism has on the internal space in terms of useful daylight, visual comfort, and lighting quality. The overall aim of the study was to gain more knowledge of the daylighting effects of ETFE cushions in façade systems [1]. Moreover, to understand the daylighting benefits switchable ETFE cushions [2] could generate when employed in double-skin façade as part of energy retrofitting measures to reduce the energy consumption of buildings. For this purpose, a virtual office space enclosed with an ETFE double-skin façade was evaluated using dynamic daylighting metrics. The simulation study was based on ray-tracing methods, using Radiance [3] software for calculating illuminance levels across a test grid within the office space. To account for the light scattering and angle dependent optical behaviour of double-curved ETFE cushions, bidirectional-scatteringdistribution-function (BSDF) was employed based on experimental measurements of spectral transmittance. The simulation scenarios included different window-to-wall ratios, ranging from a small window size of $30 \%$ to an almost full glazed façade of $90 \%$. The simulation was based on annual weather data with hourly values to produce a comprehensive picture of the daily and seasonal daylighting performance in a Mediterranean climate. Outcomes of the simulations provided numerical results expressed with dynamic daylight metrics, like useful daylight illuminance (UDI), daylight illuminance uniformity ratio (UR) and daylight glare probability (DGP). The results showed that compared to a standard glazed façade, a double-skin façade with switchable ETFE cushions could significantly reduce glare, providing better working conditions. Useful daylight illuminance increased when a switchable ETFE double-skin façade was applied, and generally, the light was more evenly distributed throughout the room with less high contrasts areas. These findings were supported with false colour illuminance renderings of the space and grid mapping of the results plotted in plan and section view. This paper reports on using for the first-time physics-based BSDF data for weatherbased five-phase daylighting simulations of switchable ETFE cushion structures. This novel approach, in combination with an integrated software workflow creating parametrized building models, suggests new ways of analysing energy-efficient building solutions with ETFE foil constructions.
\end{abstract}

\section{REFERENCES}

[1] Grunwald, G., Mechanisch vorgespannte, doppellagige Membranmodule in ihrer Anwendung als zweite Gebäudehülle, Berlin, 2007.

[2] LeCuyer, A., ETFE. Technology and Design. Basel, Switzerland: Birkhauser Verlag AG., 2008.

[3] Ward, G. L. and Shakespeare, R., Rendering with Radiance: the art and science of lighting visualization, Morgan Kaufmann Publishers Inc., 1998, p. 664. 